\title{
Maternal thyroxine and 3,5,3'-tri-iodothyronine kinetics in near-term pregnant rats at two different levels of hypothyroidism
}

\author{
P M Versloot, D van der Heide, J P Schröder-van der Elst and L Boogerd \\ Department of Human and Animal Physiology, Agricultural University, Haarweg 10, 6709 PJ Wageningen, The Netherlands \\ (Correspondence should be addressed to D van der Heide)
}

\begin{abstract}
Thyroid hormones are extremely important for development of the fetal central nervous system. Thyroidectomy results in severe hypothyroidism. In this study two levels of maternal hypothyroidism were reached by administration of different amounts of thyroxine $\left(\mathrm{T}_{4}\right)$ and 3,5,3'-tri-iodothyronine $\left(\mathrm{T}_{3}\right)$ to thyroidectomized pregnant rats. We examined the production, distribution and transport of $\mathrm{T}_{4}$ and $\mathrm{T}_{3}$ by performing a kinetic experiment (three-compartment analysis) with intact and thyroidectomized near-term pregnant rats which received either very low $(\mathrm{Tx}+$ low $\mathrm{TH})$ or normal $(\mathrm{Tx}+\mathrm{TH})$ doses of $\mathrm{T}_{4}$ and $\mathrm{T}_{3}$. Despite administration of normal doses of thyroid hormones, plasma TSH was still elevated in the Tx $+\mathrm{TH}$ rats, meaning that these rats were still mildly hypothyroid. The Tx + lowTH rats were markedly hypothyroid, the plasma $\mathrm{T}_{4}$ and $\mathrm{T}_{3}$ levels being very low. In the mildly hypothyroid rats the transport of $\mathrm{T}_{4}$ from plasma to the fast pool and vice versa was decreased compared with intact near-term pregnant rats. This could imply that much less $\mathrm{T}_{4}$ is transported to the feto-placental compartment. Liver type I deiodinase was decreased, resulting in lowered plasma $\mathrm{T}_{3}$ values. In the markedly hypothyroid rats all pools and rates of transport of $\mathrm{T}_{4}$ and $\mathrm{T}_{3}$ were greatly decreased. In conclusion, even mild hypothyroidism, despite normal plasma $\mathrm{T}_{4}$ values, results in significant changes, especially in maternal $\mathrm{T}_{4}$ transport. We suggest that even mild maternal hypothyroidism will have a negative effect on the availability of maternal $\mathrm{T}_{4}$ for fetuses.
\end{abstract}

European Journal of Endocrinology 138 113-119

\section{Introduction}

Thyroid hormones are extremely important for fetal development, especially of the central nervous system. In man, the children of mothers who were hypothyroid during pregnancy show a high incidence of behavioral and neurological disorders (1).

Rat studies have demonstrated that maternal hypothyroidism during pregnancy has irreversible effects on brain development, as indicated by a decrease in the activity of various cell marker enzymes in the brain of the progeny (2). The influence of maternal hypothyroidism on fetal development is particularly dramatic during the first half of the gestational period (3). However, even after the fetal thyroid starts to function, on day 17.5-18 of gestation, maternal thyroid hormones contribute to the fetal iodothyronine pool (4). The effects of maternal thyroidectomy, resulting in severe hypothyroidism, on fetal development and thyroid hormone levels have been studied extensively by the Madrid group (5-7). They demonstrated a decrease in the number of fetuses and the fetal body weight of thyroidectomized dams (5-7). Maternal plasma thyroxine $\left(\mathrm{T}_{4}\right)$ and 3,5,3'-tri-iodothyronine $\left(\mathrm{T}_{3}\right)$ levels decreased markedly, while thyrotropin
(TSH) was highly elevated in thyroidectomized rats. $\mathrm{T}_{4}$ and $\mathrm{T}_{3}$ concentrations were decreased in both liver and brain tissue $(6,8,9)$. The concentrations of $\mathrm{T}_{4}$ and $\mathrm{T}_{3}$ in embryonic tissues from thyroidectomized dams were undetectable before the onset of fetal thyroid function (5). At the end of gestation, on day 21, fetal plasma TSH was elevated ( 3 ) and the plasma $\mathrm{T}_{4}$ and $\mathrm{T}_{3}$ levels of the fetuses of thyroidectomized dams were similar (7) or even slightly elevated $(6,9)$ compared with those of intact dams. Total thyroidal $\mathrm{T}_{4}$ and $\mathrm{T}_{3}$ levels in fetuses from thyroidectomized dams had decreased markedly by the end of gestation (7). The fetal liver $\mathrm{T}_{4}$ concentration was decreased, whereas such a change was not found for hepatic $\mathrm{T}_{3}$. The deiodinase type I (ID-I) activity in fetal liver had decreased by $50 \%$ (7). No effect of maternal thyroidectomy on $\mathrm{T}_{4}$ and $\mathrm{T}_{3}$ concentrations in fetal brain on day 20 was found; in contrast, an increase in the cerebral $\mathrm{T}_{4}$ and $\mathrm{T}_{3}$ concentrations on day 21 was reported $(5,6)$.

Euthyroidism can be restored in thyroidectomized rats by administration of both $\mathrm{T}_{4}$ and $\mathrm{T}_{3}(10)$. If the amount of thyroid hormones administered is less than the amount normally produced, the animal will still be hypothyroid. In the present study two levels of thyroid hormone status were achieved by the administration of 
different amounts of $\mathrm{T}_{4}$ and $\mathrm{T}_{3}$ to thyroidectomized pregnant rats.

The aim of our study was to examine the effects of a mild and a marked hypothyroid state on maternal thyroid hormone metabolism in the near-term pregnant rat. $\mathrm{T}_{4}$ and $\mathrm{T}_{3}$ metabolism, distribution, and transport were examined by performing kinetic studies using the three-compartmental model of distribution and metabolism developed by DiStefano $(11,12)$. In this model three compartments can be distinguished: (i) the plasma; (ii) tissues that exchange $\mathrm{T}_{4}$ and $\mathrm{T}_{3}$ with plasma at a fast rate, the fast pool; and (iii) tissues which exchange at a slow rate, the slow pool. Liver and kidney are considered to be the main components of the fast pool, whereas skin, muscle and brain belong to the slow pool $(11,12)$. Previously we suggested that in normal near-term pregnant rats $\mathrm{T}_{4}$ is transported very rapidly from plasma to the feto-placental compartment (13). In the present study we compared the transport of maternal thyroid hormones to the feto-placental compartment during different levels of hypothyroidism. The mildly hypothyroid rats are of special interest; will there already be an effect on maternal thyroid hormone metabolism, and is the maternal contribution of thyroid hormones to the fetal compartment affected?

\section{Materials and methods}

\section{Animals and diet}

Female Wistar rats (CPB/WU, Iffa Credo, Brussels, Belgium) weighing $150 \mathrm{~g}$ were rendered hypothyroid by means of ${ }^{131} \mathrm{I}$ thyroid ablation (a single intraperitoneal injection of $\left.15 \mathrm{MBq}(0.4 \mathrm{mCi}) \mathrm{Na}^{131} \mathrm{I}\right)$. One week before and one week after radiothyroidectomy the rats received iodide-free American Institute of Nutrition (AIN) food (14). Subsequently iodide-rich AIN food ( $40 \mu \mathrm{g}$ KI per $\mathrm{g}$ food) was given for 5 days to wash the ${ }^{131}$ I out of the animals' system. During the rest of the experiment the animals received AIN food (dry powder mixed with distilled water $(60 \%$ dry weight:40\% water)) containing $55 \mathrm{ng}$ iodide/g food.

Intact, age-matched controls also consumed AIN food with $55 \mathrm{ng}$ iodide/g food.

Hypothyroidism was demonstrated by undetectable plasma $\mathrm{T}_{4}$ levels six weeks after radiation. No sooner than two months after radiothyroidectomy the rats were mated. Until mating the rats received $0.25 \mu \mathrm{g} \mathrm{T}$ daily. Mating was confirmed by the presence of sperm in a vaginal lavage the following morning, called day 0 of gestation.

\section{Design of the study}

Three groups of rats were used: (i) intact: intact, pregnant euthyroid rats; (ii) $\mathrm{Tx}+\mathrm{TH}$ : pregnant radiothyroidectomized (Tx) rats on high $\mathrm{T}_{4}$ and $\mathrm{T}_{3}(0.25 \mu \mathrm{g}$ $\mathrm{T}_{3}$ and $2.5 \mu \mathrm{g} \mathrm{T}_{4}$ per day added to the AIN diet); (iii) $\mathrm{Tx}+$ low $\mathrm{TH}$ : pregnant radiothyroidectomized rats on low $\mathrm{T}_{4}$ and $\mathrm{T}_{3}\left(0.01 \mu \mathrm{g} \mathrm{T}_{3}\right.$ and $0.1 \mu \mathrm{g} \mathrm{T}_{4}$ per day added to the AIN diet).

$\mathrm{T}_{4}$ and $\mathrm{T}_{3}$ were purchased from Sigma (St Louis, MO, USA).

Kinetic experiments were performed on day 19 of gestation. Twenty-four hours after the kinetic experiment the animals were killed; maternal blood, liver, brain and pituitary were collected.

The experiments were approved by the University Committee on Animal Care and Use of the Agricultural University of Wageningen.

\section{Kinetic and analytical protocols}

$\left[{ }^{125} \mathrm{I}\right] \mathrm{T}_{4}$ and $\left[{ }^{131} \mathrm{I}\right] \mathrm{T}_{3}$ (specific activity 80 and $130 \mathrm{MBq} / \mu \mathrm{g}$ (2200 and $3500 \mu \mathrm{Ci} / \mu \mathrm{g}$ ) respectively) were pre-pared in our laboratory $(15,16) . \mathrm{Na}^{125} \mathrm{I}$ and $\mathrm{Na}^{131}$ I were obtained from Amersham (Arlington Heights, IL, USA); L-T 3 and 3,5-L-di-iodothyronine, the respective substrates for labeling, were purchased from Sigma. Purity of the tracers was assessed by means of HPLC.

Via a cannula inserted into the right jugular vein (17) the rats received a $400 \mu \mathrm{l}$ bolus injection of a solution of $3700 \mathrm{~Bq}(10 \mu \mathrm{Ci})\left[{ }^{125} \mathrm{I}\right] \mathrm{T}_{4}$ and $3700 \mathrm{~Bq}(10 \mu \mathrm{Ci})$ $\left[{ }^{131} \mathrm{I}\right] \mathrm{T}_{3}$ in saline containing heparin $(0.3 \mathrm{U} / \mathrm{ml}$; Organon, Tilburg, The Netherlands), ticarcillin $(0.4 \mathrm{mg} / \mathrm{ml}$; Ticarpen, Beecham S.A., Heppignies, Belgium) and 5\% normal rat serum. Ticarcillin was added to solutions containing labeled iodothyronines to prevent eventual bacterial infections and reduce artefactual deiodination, as described by Van Doorn et al. (18).

Blood samples of $0.2 \mathrm{ml}$ were taken at 1, 4.5, 10, 23, 44, 115, 202 and $315 \mathrm{~min}$; $0.4 \mathrm{ml}$ samples were drawn at $465,600,900,1200$ and $1440 \mathrm{~min}$, being the optimal time schedule according to DiStefano et al. $(11,12)$.

Fifty to one hundred microliters plasma (in duplicate) were used to assess the total ${ }^{131} \mathrm{I}$ and ${ }^{125} \mathrm{I}$ activities. The plasma samples were extracted with ethanol/ammonia $(25 \%)(197: 3 \mathrm{v} / \mathrm{v})$ containing $0.1 \mathrm{mmol} / \mathrm{l}$ propylthiouracil (PTU). The dried extracts were dissolved in $0.1 \mathrm{ml}$ $0.2 \mathrm{~mol} / \mathrm{l}$ ammonia containing carrier $\mathrm{T}_{4}, \mathrm{~T}_{3}$ and $\mathrm{KI}$ $(1 \mathrm{mg} / 10 \mathrm{ml})$ and subjected to HPLC to separate the iodothyronines, according to the method described by Schröder-van der Elst and van der Heide (19).

The endogenous concentrations of $\mathrm{T}_{4}$ and $\mathrm{T}_{3}$ in plasma were measured by means of a specific rat RIA (20) of samples taken via the cannula directly before the kinetic experiments were performed.

Plasma TSH was measured by the specific RIA developed for the rat by the National Institute of Diabetes and Digestive and Kidney Diseases of the National Institute of Health (USA). Reference preparation RP-2 was used as a standard.

\section{Calculations}

The percentage doses of $\left[{ }^{131} \mathrm{I} \mathrm{T}_{3}\right.$ and $\left[{ }^{125} \mathrm{I}\right] \mathrm{T}_{4}$ per $\mathrm{ml}$ plasma were calculated from the total radioactivities 
and the $\left[{ }^{131} \mathrm{I}\right] \mathrm{T}_{3}$ and $\left[{ }^{125} \mathrm{I}\right] \mathrm{T}_{4}$ distributions on the HPLC chromatogram. The percentage doses per $\mathrm{ml}$, together with the plasma volume at $\mathrm{t}(0)$ (11), were fitted individually to sums of $n=1$ to 3 exponential:

$\mathrm{Y}(\mathrm{t})=\mathrm{A} 1 \exp (\lambda \mathrm{l} * \mathrm{t})+\mathrm{A} 2 \exp (\lambda 2 * \mathrm{t})+\mathrm{A} 3 \exp (\lambda 3 * \mathrm{t})$

using the program DIMSUM, whereby A1 is expressed in $\%$ dose $/ \mathrm{ml}, \lambda 1$ in $\min ^{-1}(21)$.

To calculate the parameters of production, distribution and metabolism, the program MAMPOOL (22) was used. The sum of the three exponential functions was fitted (by weighted least squares regression analysis) to the data collected for each individual rat and, together with the plasma $\mathrm{T}_{4}$ and $\mathrm{T}_{3}$ levels, substituted into the three-compartment model, according to the kinetic $\mathrm{T}_{4}$ and $\mathrm{T}_{3}$ studies of DiStefano et al. $(11,12)$.

All data are expressed as means \pm s.E.M. Data were analyzed using the Statistical Package for Social Sciences (SPSS) (23). All data were subjected to oneway analysis of variance, and statistical differences between groups were determined by means of the modified least significant difference method.

\section{Analytical determinations}

Mitochondrial fractions from liver and brain were obtained by differential centrifugation, according to the separation scheme described by van Doorn et al. (18).

Liver and brain mitochondrial alpha-glycerophosphate dehydrogenase ( $\alpha$-GPD; EC 1.1.2.1) was measured by means of the method described by Garrib and McMurray (24).

The determination of type I deiodinase (ID-I) activity in liver homogenates was performed by the method described by Janssen et al. (25).

Protein was determined by the bicinchoninic acid (BCA) method (Pierce Europe, Oud Beijerland, The Netherlands) using bovine serum albumin as standard.

\section{Results}

\section{Body weight and plasma hormones}

Table 1 shows the body weight (BW) and plasma thyroid hormone levels. At the start of pregnancy all rats had a similar BW. Hypothyroidism affects the BW of the nearterm pregnant rat. Tx + low $\mathrm{TH}$ rats had a significantly lower BW. The BW of the fetuses of Tx + lowTH mothers was also decreased. In this group the number of viable fetuses was decreased, while more dead and resorbed fetuses were found.

Plasma $\mathrm{T}_{4}$ was markedly decreased in the $\mathrm{Tx}+$ lowTH group, while in the $\mathrm{Tx}+\mathrm{TH}$ group a normal $\mathrm{T}_{4}$ level was reached.

Plasma $\mathrm{T}_{3}$ was decreased in both Tx groups; no difference was found between the $\mathrm{Tx}+$ lowTH and $\mathrm{Tx}+\mathrm{TH}$ groups.
Plasma TSH was highly elevated in both Tx groups. In $\mathrm{Tx}+$ lowTH rats the plasma TSH level was higher than in $\mathrm{Tx}+\mathrm{TH}$ rats.

\section{$T_{4}$ kinetics}

The disappearance curves for $\mathrm{T}_{4}$, based on the mean $\mathrm{A}$ and $\lambda$ values for the three groups, are shown in Fig. 1. The slope of the regression lines for plasma was decreased in $\mathrm{Tx}+$ low $\mathrm{TH}$ rats, meaning that $\mathrm{T}_{4}$ disappeared from plasma more slowly in this group. The fractional turnover rates for all three pools were decreased (data not shown). As a result the transport between plasma and the fast pool was $10 \%$ of that for intact controls in $\mathrm{Tx}+\mathrm{TH}$ rats and only $1 \%$ in the $\mathrm{Tx}+$ lowTH group.

For $\mathrm{T}_{4}$, distribution volumes, pool sizes, and transport rates are summarized in Table 2 . The plasma clearance rate was decreased in both Tx groups, but no additional decrease was found in $\mathrm{Tx}+$ low TH rats. The calculated rate of production of $\mathrm{T}_{4}$ in the $\mathrm{Tx}+\mathrm{TH}$ group was similar to that found in intact rats. The low ' $\mathrm{T}_{4}$ production' in the $\mathrm{Tx}+$ lowTH group resulted in an equivalent decrease in the amount of $\mathrm{T}_{4}$ in all three pools. The distribution volumes of $\mathrm{T}_{4}$ remained unchanged.

The rate of transport of $\mathrm{T}_{4}$ from plasma to the fast pool and vice versa was markedly decreased in both Tx groups; an additional decrease was found in $\mathrm{Tx}+$ lowTH rats. The transport of $\mathrm{T}_{4}$ between plasma and the slow pool was only decreased in the $\mathrm{Tx}+$ low $\mathrm{TH}$ group. It also appeared that in these rats an increasing fraction of $\mathrm{T}_{4}$ was transported unidirectionally from plasma to the slow tissue pool.

The transit times in all three pools were increased in both Tx groups, but no significant change in the total residence time was found (results not shown).

\section{$T_{3}$ kinetics}

The kinetic parameters for $\mathrm{T}_{3}$ are significantly different from intact rats only in the $\mathrm{Tx}+$ low $\mathrm{TH}$ group. The fractional rate of turnover of $\mathrm{T}_{3}$ in plasma and the transport rates from plasma to the tissue pools were decreased (data not shown).

Most changes found in the distribution, metabolism and transport of $\mathrm{T}_{3}$ (Table 3) were similar for the $\mathrm{Tx}+\mathrm{TH}$ and $\mathrm{Tx}+$ low TH groups. The plasma clearance rate for $\mathrm{T}_{3}$ was decreased. The plasma appearance rate and the production rate for $\mathrm{T}_{3}$ were diminished in all $\mathrm{Tx}$ rats. The total distribution volume as well as the distribution volume of the tissue pools was reduced only in the $\mathrm{Tx}+$ low $\mathrm{TH}$ group. In all pools the amount of $\mathrm{T}_{3}$ had decreased in both Tx groups. The transport of $\mathrm{T}_{3}$ in all directions was reduced.

No significant changes, except an increase in the transit time for plasma $(0.6 \pm 0.06 \mathrm{~min}$ and $1.2 \pm$ $0.15 \mathrm{~min}$ for intact and $\mathrm{Tx}+$ lowTH rats respectively), were found for the transit times and the total residence time of $\mathrm{T}_{3}$. 
Table 1 Body weight and plasma thyroid hormone concentrations in the intact, $\mathrm{Tx}+\mathrm{TH}$ and $T x+$ lowTH groups. Values are means \pm S.E.M.

\begin{tabular}{lccc}
\hline & $\begin{array}{c}\text { Intact group } \\
(n=8)\end{array}$ & $\begin{array}{c}\text { Tx }+ \text { TH group } \\
(n=7)\end{array}$ & $\begin{array}{c}\text { Tx + lowTH group } \\
(n=8)\end{array}$ \\
\hline Body wt on day 0 $(\mathrm{g})$ & $226 \pm 3$ & $229 \pm 4$ & $228 \pm 5$ \\
Body wt on day 19 $(\mathrm{g})$ & $299 \pm 7$ & $300 \pm 3$ & $252 \pm 5^{\text {*\# }}$ \\
No. of fetuses & $11 \pm 1$ & $9 \pm 1$ & $7 \pm 2$ \\
Fetal body wt $(\mathrm{g})$ & $4.24 \pm 0.07$ & $4.14 \pm 0.06$ & $3.38 \pm 0.19^{\star \#}$ \\
$\mathrm{~T}_{4}(\mathrm{nmol} / \mathrm{l})$ & $23.6 \pm 1.6$ & $30.6 \pm 3.1$ & $4.0 \pm 0.9^{\text {*\# }}$ \\
$\mathrm{T}_{3}(\mathrm{nmol} / \mathrm{l})$ & $0.50 \pm 0.06$ & $0.28 \pm 0.05^{\dagger}$ & $0.21 \pm 0.01^{*}$ \\
$\mathrm{TSH}(\mathrm{ng} / \mathrm{ml})$ & $0.56 \pm 0.08$ & $4.57 \pm 0.61^{\dagger}$ & $7.83 \pm 0.32^{* \#}$ \\
\hline
\end{tabular}

$P<0.05:{ }^{\dagger} \mathrm{Tx}+\mathrm{TH}$ vs intact, ${ }^{*} \mathrm{Tx}+$ lowTH vs intact, ${ }^{\#} \mathrm{Tx}+$ lowTH vs $\mathrm{Tx}+\mathrm{TH}$.

\section{Enzyme activities}

The $\alpha$-GPD activities in liver and brain are shown in Fig. 2. Hepatic $\alpha$-GPD activity was reduced in the $\mathrm{Tx}+\mathrm{TH}$ group; an even stronger decrease was found for the Tx + lowTH group. No effect of hypothyroidism on $\alpha$-GPD activity in the brain could be demonstrated.

ID-I activity (in $\mathrm{mOd} / \mathrm{min} / \mathrm{mg}$ protein) was diminished in all Tx rats: $267 \pm 13,147 \pm 16$, and $73 \pm 8$ for intact, $\mathrm{Tx}+\mathrm{TH}$ and $\mathrm{Tx}+$ lowTH rats respectively. Thus the strongest reduction was found in the $\mathrm{Tx}+$ lowTH rats.

\section{Discussion}

Thyroidectomy resulted in a lower increase in body weight during pregnancy. This is due not only to the diminished weight of the mother, but also to reduction of the fetal compartment. Treatment of the Tx animals with $\mathrm{T}_{4}$ and $\mathrm{T}_{3}(\mathrm{Tx}+\mathrm{TH})$ normalized the body weights of mother and fetus.

Since the plasma thyroid hormone and TSH levels were not normal, the Tx $+\mathrm{TH}$ group was certainly not euthyroid; we describe them as mildly hypothyroid. Tx animals which received a very low dose of $\mathrm{T}_{4}$ and $\mathrm{T}_{3}$ $(\mathrm{Tx}+$ low $\mathrm{TH})$ were markedly hypothyroid, the levels of plasma $\mathrm{T}_{4}$ and $\mathrm{T}_{3}$ being very low.

Hypothyroidism is known to influence thyroid hormone metabolism. In this study we concentrated on the effects of hypothyroidism on maternal thyroid hormone metabolism. The most important information about the effects of hypothyroidism on the availability of maternal thyroid hormones for fetuses will be obtained from the mildly hypothyroid group; does this state already have an effect on maternal-fetal transport ?

Despite normal plasma $\mathrm{T}_{4}$ values in the mildly hypothyroid group, the transport of $\mathrm{T}_{4}$ from plasma to the fast pool, compared with intact near-term pregnant rats, was already strongly reduced; in markedly hypothyroid rats almost no $\mathrm{T}_{4}$ was transported to the fast pool. Previously we suggested that in pregnant rats the fast pool consists of the liver, the kidney $(11,12)$, and the feto-placental compartment. In intact rats pregnancy results in a pronounced increase in the transport of $\mathrm{T}_{4}$ from plasma to the fast pool (13).
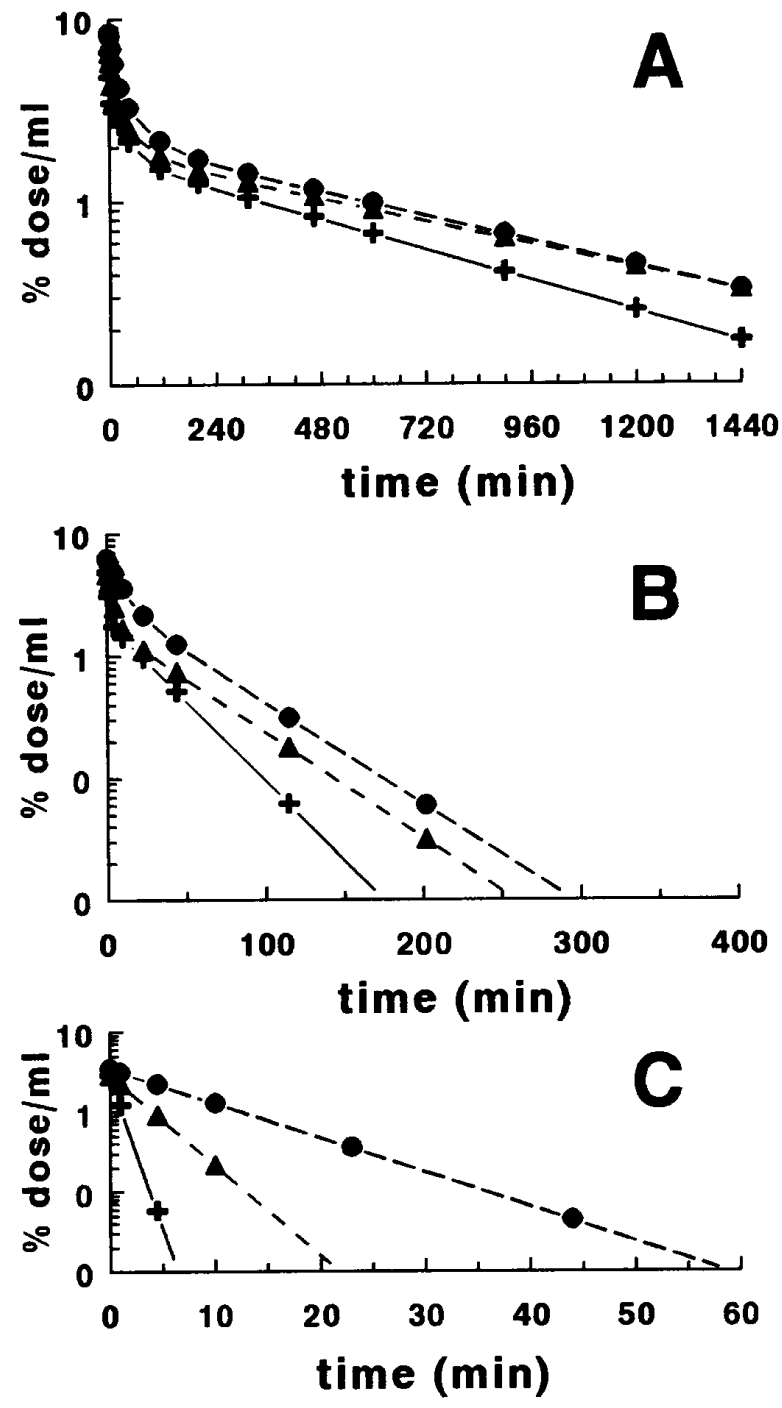

Figure $1 \mathrm{~T}_{4}$ disappearance curves obtained with a three exponential model. (A) Plot of logy(t) (in \% dose/ml) against time, with the least squares regression line on the final straight part of the curve, giving estimates of coefficient $A 3$ and exponent $\lambda 3$. (B) Plot of log $\left[y(t)-A 3 \exp \left(\lambda 3^{*} t\right)\right]$ against time, with the least squares regression line on the curve, giving estimates of coefficient $A 2$ and exponent $\lambda 2$. (C) Plot of $\log \left[y(t)-A 3 \exp \left(\lambda 3^{*} t\right)-A 2 \exp \left(\lambda 2^{*} t\right)\right]$ against time, giving estimates of coefficient $A 1$ and exponent $\lambda 1$. (+) Intact; $(\boldsymbol{\Delta}) \mathrm{Tx}+\mathrm{TH}$; (•) Tx + lowTH groups. 
Table 2 Parameters of distribution, volumes, pool sizes, and rates of transport of $T_{4}$ (expressed per $100 \mathrm{~g}$ body weight) in the intact, $\mathrm{Tx}+\mathrm{TH}$ and $\mathrm{Tx}+$ lowTH groups. Values are means \pm S.E.M.

\begin{tabular}{lccc}
\hline & Intact group & Tx + TH group & Tx + lowTH group \\
\hline PCR (ml/h) & $1.64 \pm 0.04$ & $1.19 \pm 0.07^{\dagger}$ & $1.26 \pm 0.09^{*}$ \\
PR (pmol/h) & $38.5 \pm 2.5$ & $35.6 \pm 2.7$ & $4.7 \pm 1.0^{\text {*\# }}$ \\
Vtotal (ml) & $17.6 \pm 1.0$ & $16.6 \pm 0.8$ & $17.4 \pm 2.4$ \\
Vp (ml) & $4.9 \pm 0.1$ & $5.0 \pm 0.1$ & $4.8 \pm 0.2$ \\
V2 (ml) & $3.8 \pm 0.4$ & $3.8 \pm 0.7$ & $2.4 \pm 0.5$ \\
V3 (ml) & $8.9 \pm 0.6$ & $7.8 \pm 0.3$ & $10.2 \pm 2.6$ \\
Qtotal (pmol) & $437 \pm 32$ & $519 \pm 78$ & $64 \pm 14^{* \#}$ \\
Qp (pmol) & $116 \pm 6$ & $156 \pm 20$ & $19 \pm 5^{\text {*\# }}$ \\
Q2 (pmol) & $88 \pm 9$ & $122 \pm 33$ & $9 \pm 3^{\text {*\# }}$ \\
Q3 (pmol) & $207 \pm 17$ & $239 \pm 30$ & $36 \pm 9^{\text {*\# }}$ \\
TRpf (pmol/h) & $2542 \pm 390$ & $794 \pm 177^{\dagger}$ & $33 \pm 8^{*}$ \\
TRfp (pmol/h) & $2523 \pm 389$ & $776 \pm 177^{\dagger}$ & $31 \pm 8^{*}$ \\
DRfo (pmol/h) & $19.3 \pm 1.2$ & $17.8 \pm 1.3$ & $2.4 \pm 0.5^{\text {*\# }}$ \\
TRps (pmol/h) & $195 \pm 36$ & $143 \pm 43$ & $16 \pm 4^{\text {*\# }}$ \\
TRsp (pmol/h) & $176 \pm 35$ & $125 \pm 43$ & $13 \pm 4^{*}$ \\
DRso (pmol/h) & $19.3 \pm 1.2$ & $17.8 \pm 1.3$ & $2.4 \pm 0.5^{\text {*\# }}$ \\
\% PF & $92.9 \pm 0.8$ & $85.0 \pm 2.3$ & $67.2 \pm 10.0^{*}$ \\
\% PS & $7.1 \pm 0.8$ & $15.0 \pm 2.3$ & $32.8 \pm 10.0^{*}$ \\
\hline PCR &
\end{tabular}

PCR, plasma clearance rate, $P R$; production rate; $V$, plasma equivalent distribution volume; $Q$, pool quantity; TRpf, TRfp, TRps, and TRsp, rates of transport between plasma and the fast and slow pools respectively, in each direction; DRfo and DRso, disposal rate from fast and slow pool respectively; \% PF and \% PS, fraction of $\mathrm{T}_{4}$ in plasma transported unidirectionally to the fast and slow tissue pools respectively; p, plasma; 2 , fast pool; 3 , slow pool.

$P<0.05:{ }^{\dagger} \mathrm{Tx}+\mathrm{TH}$ vs intact, ${ }^{*} \mathrm{Tx}+$ lowTH vs intact, ${ }^{\sharp} \mathrm{Tx}+$ lowTH vs Tx $+\mathrm{TH}$.

It is unlikely that the total decrease in the transport of $\mathrm{T}_{4}$ to the fast pool in mildly hypothyroid rats can be explained solely by a decrease in the transport of $\mathrm{T}_{4}$ to the liver and kidney. This implies, therefore, that even in a mildly hypothyroid situation the transport of maternal
$\mathrm{T}_{4}$ to the placenta can also be diminished. This is very important, because $\mathrm{T}_{4}$ plays a major role in the development of the fetal central nervous system. Only maternal $\mathrm{T}_{4}$ is able to mitigate fetal cerebral $\mathrm{T}_{4}$ and $\mathrm{T}_{3}$ deficiency before the fetal thyroid starts to function (8).

Table 3 Parameters of distribution, volumes, pool sizes, and rates of transport of $\mathrm{T}_{3}$ (expressed per $100 \mathrm{~g}$ body weight) in the intact, $\mathrm{Tx}+\mathrm{TH}$ and $\mathrm{T} x+$ lowTH groups. Values are means \pm S.E.M.

\begin{tabular}{|c|c|c|c|}
\hline & Intact group & $\mathrm{Tx}+\mathrm{TH}$ group & Tx + lowTH group \\
\hline PCR $(\mathrm{ml} / \mathrm{h})$ & $25.0 \pm 2.4$ & $17.6 \pm 1.3^{\dagger}$ & $16.8 \pm 1.9^{*}$ \\
\hline PAR (pmol/h) & $12.2 \pm 1.2$ & $4.9 \pm 0.9^{\dagger}$ & $3.6 \pm 0.5^{\star}$ \\
\hline $\mathrm{PR}(\mathrm{pmol} / \mathrm{h})$ & $13.5 \pm 1.1$ & $5.5 \pm 1.0^{\dagger}$ & $4.2 \pm 0.8^{*}$ \\
\hline Vtotal (ml) & $201 \pm 20$ & $173 \pm 13$ & $138 \pm 7^{*}$ \\
\hline $\mathrm{Vp}(\mathrm{ml})$ & $4.8 \pm 0.1$ & $5.4 \pm 0.6$ & $5.6 \pm 0.5^{*}$ \\
\hline V2 (ml) & $28.3 \pm 3.0$ & $28.1 \pm 2.7$ & $17.3 \pm 1.3^{* \#}$ \\
\hline V3 (ml) & $200 \pm 37$ & $139 \pm 11$ & $115 \pm 7^{*}$ \\
\hline Qtotal (pmol) & $115 \pm 19$ & $49 \pm 9^{\dagger}$ & $29 \pm 2^{*}$ \\
\hline Qp (pmol) & $2.4 \pm 0.3$ & $1.5 \pm 0.2^{\dagger}$ & $1.1 \pm 0.1^{*}$ \\
\hline Q2 (pmol) & $13.8 \pm 1.3$ & $7.9 \pm 1.3^{\dagger}$ & $3.6 \pm 0.3^{\star \#}$ \\
\hline Q3 (pmol) & $99 \pm 19$ & $44 \pm 12^{\dagger}$ & $24 \pm 2^{*}$ \\
\hline TRpf (pmol/h) & $205 \pm 27$ & $115 \pm 21^{\dagger}$ & $50 \pm 6^{*}$ \\
\hline TRfp (pmol/h) & $199 \pm 27$ & $112 \pm 20^{\dagger}$ & $48 \pm 6^{*}$ \\
\hline DRfo (pmol/h) & $6.1 \pm 0.6$ & $2.5 \pm 0.5^{\dagger}$ & $1.8 \pm 0.3^{*}$ \\
\hline TRps (pmol/h) & $53.3 \pm 13.4$ & $16.5 \pm 2.6^{\dagger}$ & $10.3 \pm 0.8^{*}$ \\
\hline TRsp (pmol/h) & $54.9 \pm 13.8$ & $16.9 \pm 2.7^{\dagger}$ & $10.6 \pm 0.9^{*}$ \\
\hline DRso (pmol/h) & $7.4 \pm 0.6$ & $3.0 \pm 0.6^{\dagger}$ & $2.5 \pm 0.5^{*}$ \\
\hline$\% \mathrm{PF}$ & $80.5 \pm 3.4$ & $86.7 \pm 1.5$ & $81.8 \pm 2.2$ \\
\hline$\%$ PS & $19.5 \pm 3.4$ & $13.3 \pm 1.5$ & $18.2 \pm 2.2$ \\
\hline
\end{tabular}

PCR, plasma clearance rate; PAR, plasma appearance rate; PR, production rate; $V$, plasma equivalent distribution volume; $Q$, pool quantity; TRpf, TRfp, TRps and TRsp, rates of transport between plasma and the fast and slow pools respectively, in each direction; DRfo and DRso, disposal rate from fast and slow pool respectively; \% PF and \% PS, fraction of $\mathrm{T}_{3}$ in plasma transported unidirectionally to the fast and slow tissue pools respectively; $p$, plasma; 2, fast pool; 3, slow pool.

$P<0.05:{ }^{\dagger}$ Tx + TH vs intact, ${ }^{*} \mathrm{Tx}+$ lowTH vs intact, ${ }^{\#} \mathrm{Tx}+$ lowTH vs Tx $+\mathrm{TH}$. 

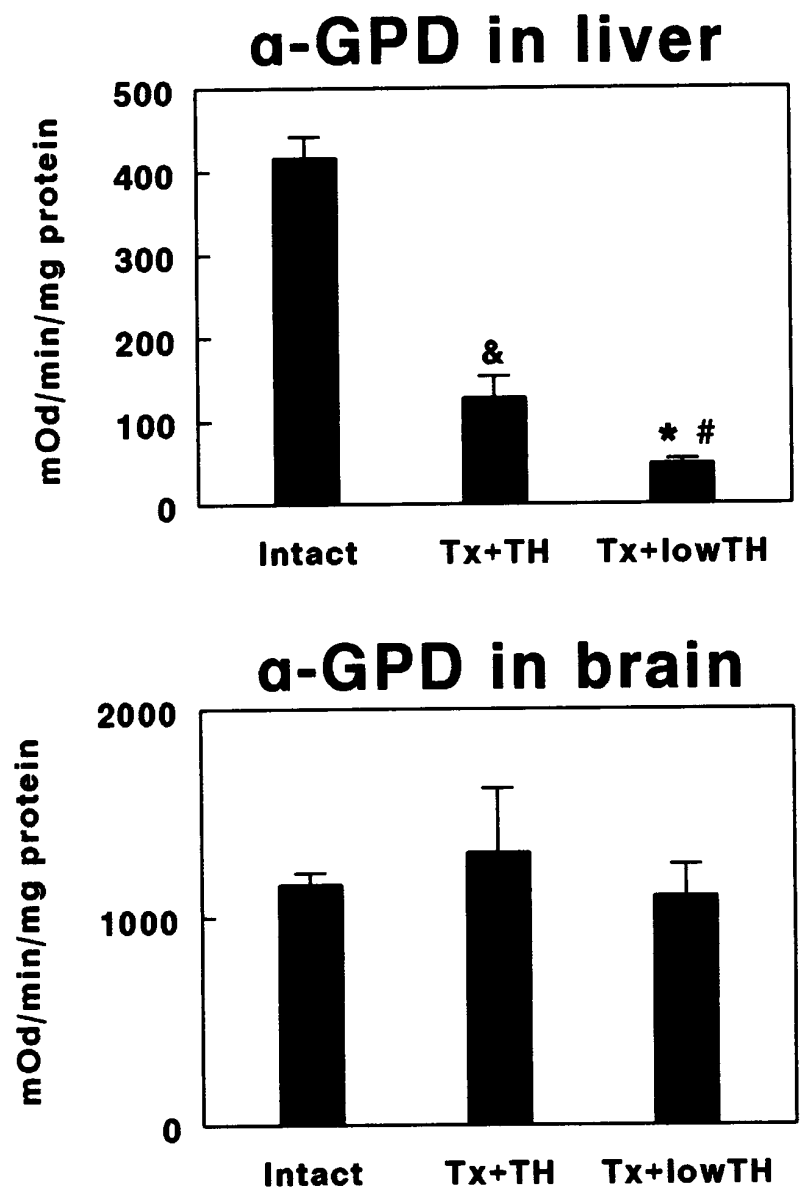

Figure $2 \alpha$-GPD in maternal liver and maternal brain in the three groups studied (intact, $\mathrm{Tx}+\mathrm{TH}, \mathrm{Tx}+$ lowTH). $P<0.05:{ }^{8} \mathrm{Tx}+\mathrm{TH}$ vs intact; * $T x+$ lowTH vs intact; ${ }^{*} T x+$ lowTH vs $T x+T H$.

The plasma $\mathrm{T}_{3}$ level in the mildly hypothyroid group was not normal. The amount of $\mathrm{T}_{3}$ added was less than the amount of $\mathrm{T}_{3}$ produced daily in intact rats $(0.25 \mu \mathrm{g}$ vs $0.60 \mu \mathrm{g}$ per day). However, since the plasma $\mathrm{T}_{4}$ level was normal, it was to be expected that $\mathrm{T}_{3}$ would also be produced locally. $\mathrm{T}_{3}$ produced locally in the liver contributes in particular to the plasma $\mathrm{T}_{3}$ level (18). However, in the hypothyroid rat the local production of $\mathrm{T}_{3}$ is decreased in the liver (18). This was also demonstrated by the decrease in ID-I activity in the liver; this can possibly be explained by the regulation of hepatic ID-I activity by $\mathrm{T}_{3}$ (26). Therefore, even in a mildly hypothyroid condition with normal plasma $\mathrm{T}_{4}$ levels, the $\mathrm{T}_{3}$ level in the liver will be reduced; this hypothesis is supported by the decrease in hepatic $\alpha$-GPD activity.

For non-pregnant thyroidectomized rats receiving an infusion of $\mathrm{T}_{4}$ and $\mathrm{T}_{3}$ it has been reported that in the event of normal plasma $\mathrm{T}_{4}$ levels and a reduced plasma $\mathrm{T}_{3}$, hepatic ID-I and cerebral ID-II activities will be normal (10). However, despite the administration of $\mathrm{T}_{4}$ in an amount which equals the amount normally produced, local $\mathrm{T}_{3}$ production was decreased in our near-term pregnant rats. It appears, therefore, that in near-term pregnant rats the effect of mild hypothyroidism is stronger than in non-pregnant rats.

Marked hypothyroidism in both non-pregnant and near-term pregnant rats results in highly reduced pools and diminished rates of transport of $\mathrm{T}_{4}$ and $\mathrm{T}_{3}$.

In conclusion, even mild hypothyroidism results in significant alterations in maternal thyroid hormone metabolism, despite normal plasma $\mathrm{T}_{4}$ levels. In particular the transport of $\mathrm{T}_{4}$ from plasma to the fast pool will be reduced. We speculate that this results in a decrease in the availability of maternal $\mathrm{T}_{4}$ for the fetuses. This could affect the development of the fetal brain, which depends mainly on maternal $\mathrm{T}_{4}$ for normal $\mathrm{T}_{3}$ values.

\section{References}

1 Man EB \& Serunian SA. Thyroid function in human pregnancy. IX. Development or retardation of 7-year-old progeny of hypothyroxine mic women. American Journal of Obstetrics and Gynecology 1976125 949-957.

2 Hadjzadeh M, Sinha AK, Pickard MR \& Ekins RP. Effect of maternal hypothyroxinaemia in the rat on brain biochemistry and adult progeny. Journal of Endocrinology 1990124 387-396.

3 Bonet B \& Herrera E. Different response to maternal hypothyroidism during the first and second half of gestation in the rat. Endocrinology 1988122 450-455.

4 Morreale de Escobar G, Calvo R, Obregon MJ \& Escobar del Rey F. Contribution of maternal thyroxine to fetal thyroxine pools in normal rats near term. Endocrinology 1990126 2765-2767.

5 Morreale de Escobar G, Pastor R, Obregon MJ \& Escobar del Rey F. Effects of maternal hypothyroidism on the weight and thyroid hormone content of rat embryonic tissues, before and after onset of fetal thyroid function. Endocrinology 1985117 1890-1900.

6 Morreale de Escobar G, Obregon MJ, Ruiz de Ona C \& Escobar del Rey F. Transfer of thyroxine from the mother to the rat fetus near term: effects on brain 3,5,3'-tri-iodothyronine deficiency. Endocrinology $19881221521-1531$.

7 Ruiz de Ona C, Morreale de Escobar G, Calvo R, Escobar del Rey F \& Obregon MJ. Thyroid hormones and $5^{\prime}$-deiodinase in the rat fetus late in gestation: effects of maternal hypothyroidism. Endocrinology 1991128 422-432.

8 Morreale de Escobar G, Obregon MJ, Ruiz de Ona C \& Escobar del Rey F. Comparison of maternal to fetal transfer of $3,5,3^{\prime}$-triiodothyronine versus thyroxine in rats, as assessed from 3,5,3'tri-iodothyronine levels in fetal tissues. Acta Endocrinologica 1989 $12020-30$.

9 Porterfield SP \& Hendrich CE. The thyroidectomized pregnant rat - an animal model to study fetal effects of maternal hypothyroidism. Advanced Experimental Medical Biology 1991 299 107-132.

10 Escobar-Morreale HF, Escobar del Rey F, Obregon MJ \& Morreale de Escobar G. Only the combined treatment with thyroxine and tri-iodothyronine ensures euthyroidism in all tissues of the thyroidectomized rat. Endocrinology 1996137 2490-2502.

11 DiStefano III JJ, Jang M, Malone TK \& Broutman M. Comprehensive kinetics of tri-iodothyronine production, distribution, and metabolism in blood and tissue pools of the rat using optimized blood sampling protocols. Endocrinology $1982110198-213$.

12 DiStefano III JJ, Malone TK \& Jang M. Comprehensive kinetics of thyroxine distribution and metabolism in blood and tissue pools of the rat from only six blood samples: dominance of large, slowly exchanging tissue pools. Endocrinology 1982111 $108-117$. 
13 Versloot PM, Gerritsen J, Boogerd L, Schröder-van der Elst JP \& van der Heide D. Thyroxine and 3,5,3'-tri-iodothyronine production, metabolism, and distribution in pregnant rat near term. American Journal of Physiology, Endocrinology and Metabolism 1994 $267860-867$.

14 Ad Hoc Committee on Standards for Nutritional Studies. Report of the American Institute of Nutrition. Journal of Nutrition 19777 1340-1348.

15 Kjeld JM, Kuku SK, Diamant I, Fraser TR, Joplin GF \& Mashiter K. Production and storage of $\left[{ }^{125} \mathrm{I}\right]$-tri-iodothyronine of high specific activity. Clinica Chimica Acta 197561 381-389.

16 Weeke J \& Orskov K. Synthesis of $\left[{ }^{125} \mathrm{I}\right]$ monolabelled $\mathrm{T}_{3}$ and $\mathrm{T}_{4}$ of maximum specific activity for radioimmunoassay. Scandinavian Journal of Clinical Laboratory Investigation 197332 357-366.

17 Roelfsema F, van der Heide D \& Smeenk D. Circadian rhythms of urinary electrolyte excretion in freely moving rats. Life Sciences $1980272303-2309$.

18 Doorn van J, van der Heide D \& Roelfsema F. Sources and quantity of 3,5,3'-tri-iodothyronine in several tissues of the rat. Journal of Clinical Investigation 198372 1778-1792.

19 Schröder-van der Elst JP \& van der Heide D. Effects of 5,5'-diphenylhydantoin on thyroxine and 3,5,3'-tri-iodothyronine concentrations in several tissues of the rat. Endocrinology 1990126 186-191.

20 Van der Heide $\mathrm{D} \&$ Visser-Ende $\mathrm{M} . \mathrm{T}_{4}, \mathrm{~T}_{3}$ and reverse $\mathrm{T}_{3}$ in the plasma of rats during the first 3 months of life. Acta Endocrinologica $198093448-454$.
21 Marino A, DiStefano III JJ \& Landaw EM. DIMSUM: an expert system for multiexponential model discrimination. American Journal of Physiology, Endocrinology and Metabolism 1992262 546-556.

22 Lindell R, DiStefano III JJ \& Landaw EM. Statistical variability of parameter bounds for n-pool unidentifiable mammillary and catenary compartmental models. Mathematical Biosciences 1988 91 175-199.

23 SPSS Inc. SPSS/PC + STATISTICS $4 \cdot 0$. McGraw-Hill, Chicago, IL: McGraw-Hill, 1990.

24 Garrib A \& McMurray WC. A sensitive, continuous spectrophotometric method for assaying $\alpha$-glycerophosphate dehydrogenase: activation by menadione. Analytical Biochemistry 1984 139 319-321.

25 Janssen PLTMK, van der Heide D, Visser TJ, Kaptein E \& Beynen AC. Thyroid function and deiodinase activities in rats with marginal iodine deficiency. Biological Trace Element Research 1994 $40237-246$.

26 Maia AL, Kieffer JD, Harney JH \& Larsen PR. Effect of 3,5,3'-triiodothyronine $\left(\mathrm{T}_{3}\right)$ administration on dio! gene expression and $\mathrm{T}_{3}$ metabolism in normal and type I deiodinase-deficient mice. Endocrinology $19951364842-4849$.

Received 28 May 1997 Accepted 29 July 1997 